특집논문(Special Paper)

방송공학회논문지 제17권 제5호, 2012년 9월 (JBE Vol. 17, No. 5, September 2012)

http://dx.doi.org/10.5909/JBE.2012.17.5.716

ISSN 1226-7953(Print)

\title{
$\mathrm{HEVC}$ 의 공간적 상관성 기반 고속 부호화 깊이 및 참조영상 결정 방법
}

이 상 용 $^{a)}$, 김 동 현 ${ }^{a)}$, 김 재 곤 ${ }^{\ddagger}$, 최 해 철 ${ }^{b)}$, 김 진 수 ${ }^{b)}$, 최 진 수 ${ }^{c}$

\section{Spatial Correlation Based Fast Coding Depth Decision and Reference Frame Selection in HEVC}

\author{
Sang-Yong Lee ${ }^{\text {a) }}$, Dong-Hyun Kim ${ }^{\text {a) }}$, Jae-Gon Kim ${ }^{\text {a }}$, Hae-Chul Choi ${ }^{\text {b) }}$, Jin-soo Kim ${ }^{\text {b) }}$, and Jin Soo Choi ${ }^{\text {c) }}$ \\ 요 약 \\ 본 논문에서는 $\mathrm{HEVC}$ (High Efficiency Video Coding) 부호화 속도 향상을 위한 최대 부호화깊이 및 참조영상 고속결정 방법을 제안 \\ 한다. 본 논문에서는 계산 복잡도 감소와 속도향상을 위하여 크게 두 가지 방법을 제안한다. 첫 번째 방법에서는 LCU(Largest Coding \\ Unit)내 각 $\mathrm{CU}$ (Coding Unit)의 최대 부호화 깊이를 제한하며, 이때 공간적인 상관성을 기반으로 주변 $\mathrm{LCU}$ 에서 사용된 최대 부호화 깊 \\ 이와 율-왜곡 비용을 이용한다. 두 번째 방법에서는 각 $\mathrm{CU}$ 의 다양한 PU(Prediction Unit) 중, 화면간 예측을 수행하는 PU에 대해서 참조 \\ 영상을 제한하며, 이때 상위 깊이 PU의 움직임 정보를 이용한다. 제안하는 방법은 항상 최대 깊이까지 부호화를 수행하는 것을 적응적으 \\ 로 제한하고, 상당한 복잡도를 요구하는 움직임 예측을 수행하는 $\mathrm{PU}$ 의 참조영상 수를 제한함으로써 계산 복잡도를 감소시킬 수 있으며, \\ 기존의 $\mathrm{HEVC}$ 참조 소프트웨어인 HM6.1 대비 약 $1.2 \%$ 정도의 비트율이 증가하면서 약 $39 \%$ 의 복잡도 감소 효과를 얻을 수 있었다.
}

\begin{abstract}
In this paper, we propose a fast decision method of maximum coding depth decision and reference frame selection in HEVC. To reduce computational complexity and encoding time of HEVC, two methods are proposed. In the first method, the maximum depth of each coding unit (CU) in a largest CU (LCU) is constrained by using the maximum coding depth used by adjacent LCUs based on the assumption that the spatial correlation is very high and rate-distortion (R-D) cost. And we constrain the number of reference pictures for prediction unit (PU) performing motion estimation by using the motion information of the upper depth PU. The proposed methods reduce computational complexity of the HEVC encoder by constraining the maximum coding depth and the reference frame. We could achieve about $39 \%$ computational complexity reduction with marginal bitrate increase of $1.2 \%$ in the comparison with HM6.1 HEVC reference software.
\end{abstract}

Keywords : HEVC, coding unit (CU), depth of $\mathrm{CU}$, fast $\mathrm{CU}$ depth decision, multiple reference pictures

a) 한국항공대학교 항공전자 및 정보통신공학부(School of Elec., Telecom. \& Comp. Eng., Korea Aerospace Univ.)

b) 한밭대학교 정보통신공학과(Dept. of Info. and Comm. Eng., Hanbat National Univ.)

c) 한국전자통신연구원 방통융합미디어연구부 실감미디어연구팀(Realistic Media Research Team, ETRI)

‡ Corresponding Author : 김재곤 (Jae-Gon, Kim)

E-mail: jgkim@kau.ac.kr

Tel: +82-2-300-0014 Fax: +82-2-3159-9257

※이 논문은 지식경제부 및 정보통신산업진흥원의 대학IT연구센터육성 지원사업(NIPA-2012-H0301-12-1006) 및 2012년도 정부(교육과학기술부)의 재원 으로 한국연구재단의 기초연구사업(2012-0006938) 지원을 받아 수행된 것임.

Manuscript received July 9, 2012 Revised August 16, 2012 Accepted August 16, 2012 


\section{I. 서 론}

$\mathrm{HD}$ (High Definition) 및 UHD(Ultra High Definition)와 같은 고해상도/고화질 비디오에 대한 요구가 증가하면서 기존의 최신 비디오 부호화 표준인 $\mathrm{H} .264 / \mathrm{AVC}^{[1][2]}$ 보다 더 높은 부호화 효율을 제공하는 고성능 압축 부호화 기술의

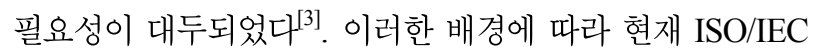
의 MPEG과 ITU-T VCEG의 공동협력팀인 JCT-VC(Joint Collaborative Team on Video Coding)에서 HEVC(High Efficiency Video Coding)라는 새로운 비디오 부호화 표준 화가 마무리 단계에 있다. HEVC는 기존 H.264/AVC 보다 두 배 이상의 높은 부호화 효율을 목표로 하고 있으며, 이 미 새로운 부호화 기술들의 채택으로 부호화 성능이 상당 히 증가하였다. 채택된 새로운 기술에는 계층적 부호화 구 조 및 변환블록 구조, Merge(움직임 정보 결합), AMVP (Advanced Motion Vector Prediction), SAO(Sample Adaptive Offset) 등[4]이 있다. 그리고 기존 H.264/AVC의 기술들을 수정/확장하여 부호화 성능을 높였지만 더불어 $\mathrm{HEVC}$ 부호화기/복호화기의 복잡도도 상당히 증가하였다. $\mathrm{HEVC}$ 표준화에서는 압축 효율뿐만 아니라 부호화기/복호 화기의 연산 복잡도도 중요하게 고려되고 있기 때문에, $\mathrm{HEVC}$ 의 복잡도를 줄이는 방안도 주요 이슈가 되고 있다.

현재 HEVC는 새롭게 부호화단위(CU: Coding Unit) 개 념을 도입하여 부호화 효율이 최대가 되는 블록 크기를 기 본 부호화 단위로 사용하는 계층적 부호화 구조를 가진다 [5]. 이는 $\mathrm{HEVC}$ 의 부호화 효율을 상당히 증가시키지만, 다 양한 $\mathrm{CU}$ 크기와 각 $\mathrm{CU}$ 에 해당하는 예측단위(PU: Prediction Unit)에 대해 모두 부호화를 수행하여 최적의 $\mathrm{CU}$ 및 $\mathrm{PU}$ 를 결정하는 과정을 포함함으로써 부호화기의 복잡 도가 상당히 증가하였으며, 최적의 $\mathrm{CU}$ 를 결정하기 위한 부 호화기의 연산 복잡도가 평균 $60 \%$ 이상으로 상당히 복잡 하다. 특히, 움직임이 적고 평탄한 영역에 해당하는 $\mathrm{LCU}$ 의 경우 성능 증가 없이 복잡도 증가만 초래할 수 있다.

그리고 $\mathrm{HEVC}$ 의 화면간 예측에서 움직임 예측(ME) 연 산의 복잡도는 새로운 부호화 툴들의 복잡도 증가로 기존 의 H.264/AVC에서 보다 전체 복잡도에서 차지하는 비중 이 많이 줄었지만 여전히 움직임 예측을 수행함에 있어 각
참조영상 리스트(listL0 및 listL1)에서 두 개 이상의 다중 참조영상 허용으로 참조영상을 선택하기 위한 복잡도는 여 전히 높다.

본 논문에서는 $\mathrm{HEVC}$ 의 높은 복잡도 문제를 해결하기 위해서 크게 두 가지 방법을 제안한다. 첫 번째 방법은 각각의 LCU에 대해 최대 부호화 깊이(coding depth)를 결 정하는 방법으로 크게 두 가지 단계로 구성된다. 먼저 이 미 부호화된 주변 LCU에서 사용한 부호화 깊이 정보를 이용하여 현재 부호화하는 LCU의 최대 부호화 깊이를 제 한한다. 그리고 앞에서 결정된 최대 부호화 깊이로 $\mathrm{LCU}$ 를 부호화 할 때, $\mathrm{n}$ 의 깊이를 가지는 $\mathrm{CU}$ 의 최적의 율-왜 곡(R-D) 비용과 $(\mathrm{n}-1)$ 의 깊이를 가지는 $\mathrm{CU}$ 의 최적의 율왜곡 비용을 비교하여 현재 $\mathrm{n}$ 의 깊이를 가지는 $\mathrm{CU}$ 를 $(n+1)$ 의 깊이를 가지는 4 개의 하위 CU로 나누어 부호화 를 수행할지 말지를 결정하여 적응적으로 최대 부호화 깊 이를 제한함으로써 최적의 $\mathrm{CU}$ 를 결정하기 위한 연산 복 잡도를 줄인다. 두 번째 방법은 현재 $\mathrm{CU}$ 와 상위 깊이 $\mathrm{CU}$ 사이의 상관성을 이용하여 현재 $\mathrm{CU}$ 의 움직임 예측 수행 시 참조영상의 후보의 수를 제한함으로써 움직임 예측의 연산 복잡도를 줄인다.

본 논문의 구성은 다음과 같다. ㅍㅈ장에서는 기존의 방법 에 대해서 살펴보고, III장에서는 제안하는 방법을 기술한 다. IV장에서는 제안하는 알고리즘을 적용한 실험결과를 분 석하고, 마지막으로 $\mathrm{V}$ 장에서 결론을 맺는다.

\section{HEVC의 계층적 부호화 구조}

$\mathrm{HEVC}$ 는 부호화 성능을 높이기 위해 계층적 부호화 구 조를 가지며, 부호화의 기본단위인 $\mathrm{CU}$ 는 $128 \times 128$ 8x8의 다양한 크기를 가질 수 있다.

그리고 부호화에 사용된 최대 부호화단위(LCU)와 최소 부호화단위(SCU: Smallest CU)의 크기는 SPS(Sequence Parameter Set)의 log2_min_coding_block_size_minus3과 $\log 2$ diff_max_min_coding_block_size 구문 요소를 통해 시그널링한다. 현재 $\mathrm{HEVC}$ 공통실험조건에서 $\log 2$ min coding_block_size_minus3는 0 이고 log2_diff_max_min 

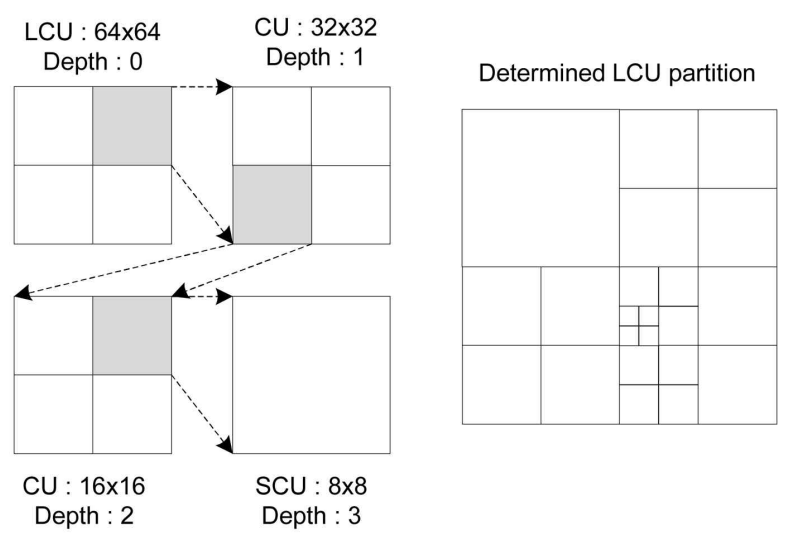

그림 1. LCU의 계층적 부호화 구조

Fig. 1. Hierarchical coding structure of LCU

coding_block_size는 3으로 $\mathrm{CU}$ 의 최대 크기는 $64 \times 64$ (LCU), 최소 크기는 $8 \times 8(\mathrm{SCU})$ 로 정의되어 있으며, 그림 1 과 같은 부호화 구조를 가진다. 또한 $\mathrm{CU}$ 는 깊이 정보를 가 지며 $64 \times 64 \mathrm{CU}$ 의 깊이는 $0,8 \times 8 \mathrm{CU}$ 의 깊이는 3 이 된다.

하나의 $\mathrm{LCU}$ 에 대해 최적의 $\mathrm{CU}$ 를 결정하는 방법은 다음 과 같다. 먼저 $\mathrm{LCU}$ 에 대해 정의된 다양한 PU로 부호화를 수행한 후, 율-왜곡 기반 최적의 PU를 찾는다. 그리고 $\mathrm{LCU}$ 는 4개의 하위 CU로 나뉘며, SPS에서 정의된 최대 깊이까 지 즉, $\mathrm{SCU}$ 까지 나뉘어 각각의 $\mathrm{CU}$ 에서 정의된 다양한 $\mathrm{PU}$ 에 대해 부호화를 수행하고 각각 최적의 $\mathrm{PU}$ 를 결정하는 재 귀적 구조를 가진다. 그리고 4개의 SCU에 대해 최적의 $\mathrm{PU}$ 가 결정되면 4 개 $\mathrm{SCU}$ 의 총 비용과 이전 깊이를 가지는 $\mathrm{CU}$ 의 비용을 비교하여 최적의 깊이를 결정하게 되며, 위와 같 은 과정을 반복하여 마지막으로 1 의 깊이에서 결정된 모든 최적의 $\mathrm{CU}$ 들의 비용과 0 의 깊이를 가지는 $\mathrm{CU}$, 즉 $\mathrm{LCU}$ 의 비용을 비교하여 그림 1 과 같이 최종적으로 하나의 LCU에 대한 최적의 $\mathrm{CU}$ 가 선택된다.

그리고 다양한 크기를 가지는 $\mathrm{CU}$ 는 그 크기마다 그림 2 와 같이 다양한 $\mathrm{PU}$ 를 가질 수 있다. $\mathrm{CU}$ 크기가 $\mathrm{SCU}$ 보다 큰 경우를 예로 들면, 하나의 $\mathrm{CU}$ 는 $2 \mathrm{Nx} 2 \mathrm{~N}$ 크기에 대해 스 킵(skip) 모드를 수행하고 최대 7가지 PU 모양에 대해 화면 간 예측을 수행하며, $2 \mathrm{Nx} 2 \mathrm{~N}$ 크기에 대해 화면내 예측을 수 행하여 율-왜곡 기반 비용이 가장 작은 $\mathrm{PU}$ 를 현재 $\mathrm{CU}$ 의 최적의 PU로 결정한다.

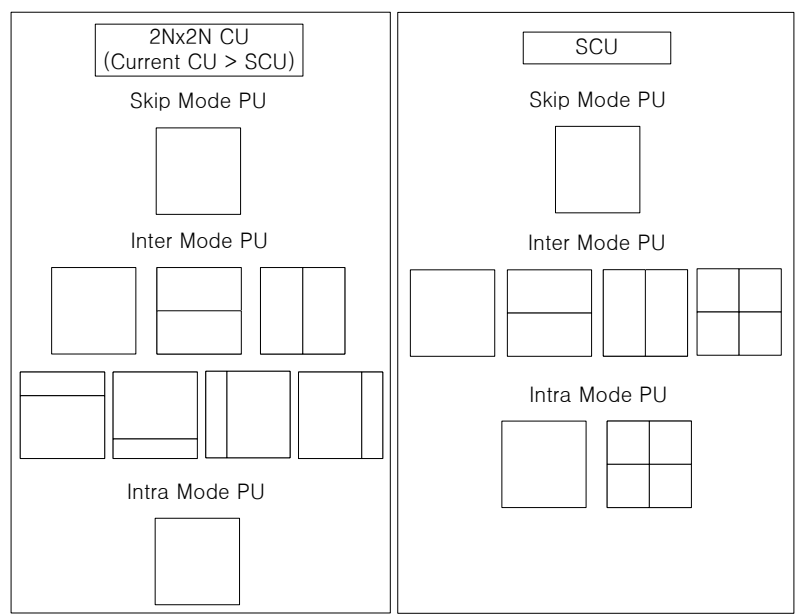

그림 2. 스킵, 화면내 예측, 화면간 예측을 위한 PU

Fig. 2. PU for skip, intra, inter prediction mode

위와 같이 $\mathrm{HEVC}$ 에서는 하나의 $\mathrm{LCU}$ 에서 $\mathrm{SCU}$ 까지의 모든 $\mathrm{CU}$ 에 대해서 최적의 $\mathrm{PU}$ 를 찾고 율-왜곡 기반으로 최 적의 $\mathrm{CU}$ 를 결정함으로써 부호화 효율을 높일 수 있으나 그 만큼 상당한 복잡도를 필요로 한다. 특히, 정적이거나 평탄한 영역의 $\mathrm{LCU}$ 인 경우 SPS에 정의된 모든 깊이에 대 해 부호화를 수행하여 최적의 $\mathrm{CU}$ 를 결정하는 것은 부호화 의 성능 이득 없이 복잡도 증가를 초래할 수 있다. 또한 다 양한 PU에 대해서 부호화를 수행하여 최적의 PU를 결정함 으로써 부호화 효율을 증가시킬 수 있지만, 동시에 상당한 복잡도도 수반된다. 특히 화면간 예측의 경우, 모든 예측방 향과 참조영상들에 대해 움직임 예측을 수행함으로써 스킵 이나 화면내 예측 보다 상당히 복잡하며, 화면간 예측을 수 행하는 $\mathrm{PU}$ 의 수도 많기 때문에 더 많은 복잡도를 필요로 한다.

이러한 HEVC 부호화기의 복잡도를 감소시키기 위한 다 양한 기법들이 제안되었고, 현재 $\mathrm{HEVC}$ 의 참조 소프트웨어 인 $\mathrm{HM}$ 에 채택되어있는 기술로 $\mathrm{CU}$ 부호화 조기 종료 기법 ${ }^{[6}$ 과 코딩 트리 프루닝(pruning) 기반 $\mathrm{CU}$ 조기 종료 기법 ${ }^{[7]}$ 이 있다. 첫 번째 방법은 $\mathrm{n}$ 의 깊이를 가지는 CU가 모든 PU 에 대해 차례로 부호화를 수행하면서 어느 PU의 휘도성분 과 색차성분들의 잔여신호가 존재하지 않는 경우, 해당 $\mathrm{CU}$ 는 나머지 PU들에 대해서 부호화 하지 않고 상기 $\mathrm{CU}$ 를 현 재 $\mathrm{CU}$ 의 최적의 $\mathrm{PU}$ 로 결정하고 다음 4 개의 하위 $\mathrm{CU}$ 로 분 
할됨으로써, 현재 $\mathrm{n}$ 의 깊이를 가지는 $\mathrm{CU}$ 부호화는 조기 종 료된다. 두 번째 방법의 경우, $\mathrm{n}$ 의 깊이를 가지는 $\mathrm{CU}$ 의 모 든 PU에 대해 부호화를 수행하여 최적의 PU를 결정하고, 이 때, $\mathrm{CU}$ 의 최적의 $\mathrm{PU}$ 가 스킵모드인 경우, 해당 $\mathrm{CU}$ 는 더 이상 4 개의 하위 $\mathrm{CU}$ 로 분할되지 않고 조기 종료된다. 상기 두 가지 방법 각각 약간의 성능 저하만으로 $\mathrm{HEVC}$ 부호화 기의 복잡도를 상당히 감소시킨다. CU부호화 조기 종료 기 법 $^{[6]}$ 은 $\mathrm{HM} 3.2$ 에서 $0.85 \%$ 의 비트량 증가에 평균 $58.8 \%$ 의 복잡도 감소를, 코딩 트리 프루닝 기반 $\mathrm{CU}$ 조기 종료 기법 ${ }^{[7]}$ 은 $\mathrm{HM} 3.1$ 에서 $0.8 \%$ 의 비트량 증가에 평균 $42 \%$ 의 복잡도 가 감소하였다.

본 논문에서는 상기 방법들과 달리 주변 LCU의 부호화 깊이 정보와 깊이에 따른 $\mathrm{CU}$ 의 비용을 이용하여 최대 부호 화 깊이를 제한하고 상위 깊이 $\mathrm{CU}$ 의 움직임 정보를 이용하 여 현재 PU의 움직임 예측에 사용되는 참조영상의 수를 제 한하여 부호화기의 연산 복잡도를 줄이는 방법을 제안한다.

\section{III. 고속 결정방법}

본 논문에서는 $\mathrm{HEVC}$ 부호화기의 복잡도를 감소시키기 위해 크게 두 가지 방법을 제안한다. 첫 번째 방법에서는 두 단계로 나누어 먼저 주변 $\mathrm{LCU}$ 의 부호화 깊이 정보를 이용하여 현재 LCU의 최대 부호화 깊이를 제한하고, 다음 으로 각 깊이에서 최적의 $\mathrm{CU}$ 율-왜곡 비용을 이용하여 적 응적으로 부호화 깊이를 제한하는 방법을 제안한다. 두 번 째 방법에서는 상위 깊이 $\mathrm{CU}$ 의 움직임 정보를 이용하여 현재 움직임 예측을 하는 PU의 참조영상을 제한하여 연산 복잡도를 줄이는 방법을 제안한다.

\section{1. 고속 최대 부호화깊이 결정 방법}

본 제안 방법에서는 현재 $\mathrm{LCU}$ 와 주변 $\mathrm{LCU}$ 의 공간적 상 관성이 높음을 이용하여 현재 LCU의 최대 부호화 깊이를 제한하며, 크게 두 단계로 나누어 실시한다. 먼저 아래 그림 3 과 같이 현재 LCU와 인접한 4 개의 주변 LCU 부호화 정 보를 이용하여 현재 $\mathrm{LCU}$ 의 최대 부호화 깊이를 제한한다.
그리고 좀 더 정확한 최대 부호화 깊이 예측을 위하여 4개 의 LCU가 모두 이미 부호화되어 부호화 정보를 이용할 수 있는 경우에만 제안 기법을 적용한다.

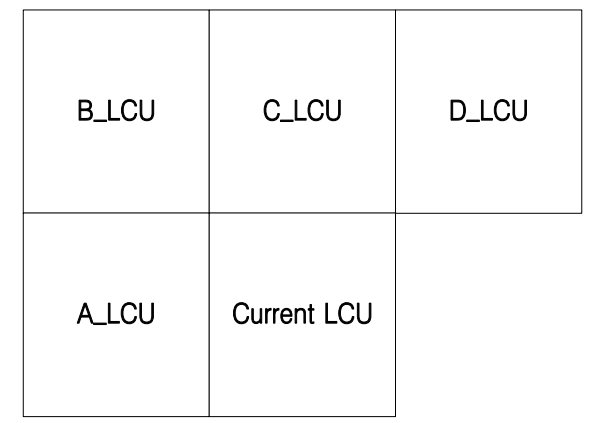

그림 3. 현재 LCU와 인접한 4 개의 LCU

Fig. 3. Current LCU and four neighboring LCUs

현재 부호화하는 $\mathrm{LCU}$ 의 최대 부호화 깊이를 예측하는 알고리즘은 아래 식과 같다.

$$
\begin{aligned}
& d_{\text {cur }}=\min \left(d_{\max }, d_{\text {pred }}+x\right) \\
& d_{\text {pred }}=\max \left(d_{A}, d_{B}, d_{C}, d_{D}\right) \\
& x=\log 2 \_d i f f \_m a x \_m i n \_c o d i n g \_b l o c k \_s i z e
\end{aligned}
$$

$d_{\text {cur }}$ 은 현재 LCU 부호화에 적용하기 위한 예측된 최대 부호화 깊이 값이고, $d_{\max }$ 는 실험조건에서 설정된 $\mathrm{LCU}$ 의 최대 부호화 깊이 값이다. $d_{p r e d}$ 는 주변 LCU들로부터 예측 된 부호화 깊이 값으로 이는 주변 4개 LCU 각각의 실제 부호화에 적용된 최대 부호화 깊이 중 가장 큰 값을 취한다. log2_diff_max_min_coding_block_size는 부호화에 적용된 $\mathrm{LCU}$ 크기와 $\mathrm{SCU}$ 크기의 차이 값으로, 결국 부호화에 적용 되는 최대 부호화 깊이를 나타낸다. 공통실험조건 ${ }^{[9]}$ 으로 예 를 들면, log2_diff_max_min_coding_block_size의 값은 3 이므로 $d_{\max }$ 의 값은 4 이고 $x$ 의 값은 3 이 된다. 그러므로 주변 $\mathrm{LCU}$ 중 하나라도 1 이상의 부호화 깊이로 부호화 되 었다면, $d_{c u r}$ 은 4로 설정이 되어 현재 LCU는 기존처럼 0 3 의 부호화 깊이를 갖는다. 그리고 주변 4개의 LCU 모두 0 의 부호화 깊이로 부호화 되었다면, 즉, 모두 LCU 그 자체 로 부호화 되었다면, $d_{c u r}$ 은 3 으로 설정이 되어 현재 $\mathrm{LCU}$ 
는 기존과 달리 0 2 의 부호화 깊이를 갖는다. 즉, 최대 부호 화 깊이가 모두 0 이면, 주변 4 개의 LCU는 평탄한 영역일 확률이 높고 현재 부호화하는 LCU도 평탄한 영역일 확률 이 높다. 따라서 이런 경우, 현재 $\mathrm{LCU}$ 는 $\mathrm{SCU}(8 \mathrm{x} 8)$ 에 대해 서 부호화를 수행하지 않음으로써 부호화기의 복잡도를 감 소시킬 수 있다.

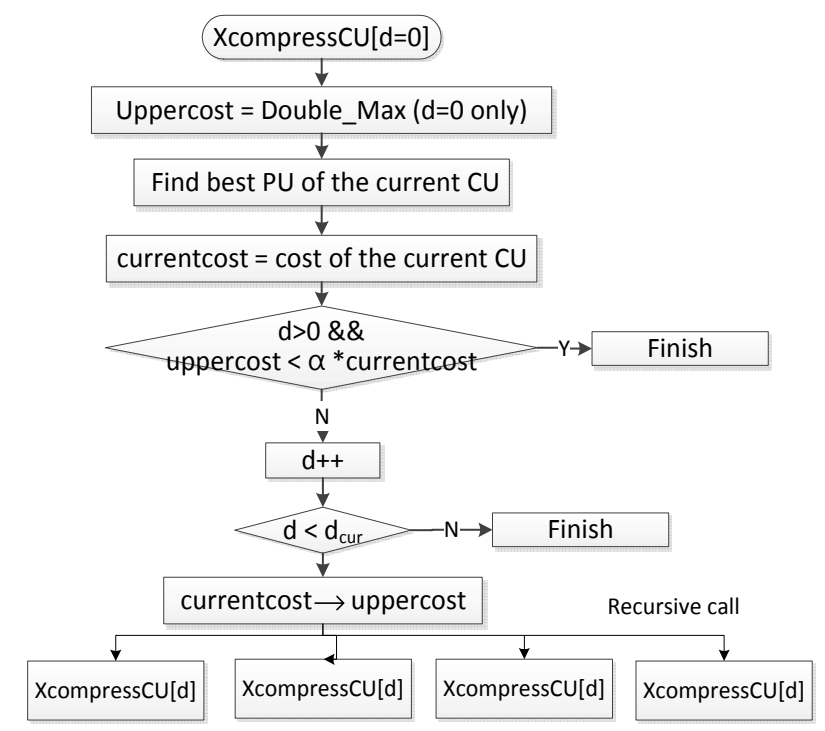

그림 4. CU 조기 종료 알고리즘

Fig. 4. Early termination algorithm of $\mathrm{CU}$ encoding

첫 번째 단계에서 현재 $\mathrm{LCU}$ 의 최대 부호화 깊이, $d_{c u r}$ 가 결정되면 LCU는 부호화를 시작하는데 앞에서 유도된 최대 부호화 깊이까지 항상 실행하지 않고, 두 번째 단계에서 그 림 4와 같은 절차에 의해 최대 부호화 깊이까지 실행하기 전에 현재 $\mathrm{CU}$ 에 대한 부호화를 적응적으로 조기 종료할 수 있다. 그림 4의 $\mathrm{CU}$ 조기 종료 알고리즘의 상세한 처리 과정은 다음과 같다. $\mathrm{xCompressCU}($ )는 깊이 $\mathrm{d}$ 에서의 $\mathrm{CU}$ 부호화 처리하는 함수로 그림 4 의 나머지 모든 과정들을 포함한다. 먼저, uppercost는 상위 부호화 깊이 $\mathrm{CU}$ 에서의 부호화 율-왜곡 비용을 나타내는데 $\operatorname{LCU}(\mathrm{d}=0)$ 에서는 Double_Max값으로 초기화 한다. currentcost는 현재 부호 화 깊이 $\mathrm{d}$ 에서의 율-왜곡 비용으로 최적의 PU에서의 율-왜 곡 비용이다. 먼저 $\mathrm{LCU}(\mathrm{d}=0)$ 를 시작으로 부호화를 시작하 여 0 의 깊이를 가지는 LCU에 대해서는 기존의 HEVC 방
법대로 최적의 $\mathrm{PU}$ 를 결정하고 현재 $\mathrm{CU}$ 의 율-왜곡 비용 (currentcost)을 저장한 뒤, 다음 4 개의 하위 $\mathrm{CU}$ 를 호출하여 부호화를 시작한다.

0 보다 큰 깊이를 가지는 $\mathrm{CU}$ 에 대한 최적의 $\mathrm{PU}$ 가 정해지 고 율-왜곡 비용(currentcost)이 정해지면 이전 깊이 $\mathrm{CU}$ 에 서 정해진 최적의 율-왜곡 비용(uppercost)과 비교를 한다. 만약 현재 $\mathrm{CU}$ 의 율-왜곡 비용의 $\mathrm{a}(0-4)$ 배에 해당하는 값이 이전 깊이 $\mathrm{CU}$ 의 율-왜곡 비용보다 크면 현재 $\mathrm{CU}$ 는 더 이 상 4 개의 하위 $\mathrm{CU}$ 로 나누어 지지 않고 종료되고, 그렇지 않은 경우, 기존의 방법대로 다음 4 개의 하위 $\mathrm{CU}$ 로 분리되 어 부호화를 진행한다. $a$ 는 현재 $\mathrm{CU}$ 의 율-왜곡 비용에 대 한 가중치이다. 이 때, 다음 부호화 깊이 d가 예측 부호화 깊이 $d_{c u r}$ 와 같거나 크면 하위 $\mathrm{CU}$ 부호화를 진행하지 않고 조기 종료하게 된다.

결국, 제안한 알고리즘은 $\mathrm{n}$ 의 깊이를 가지는 4 개 $\mathrm{CU}$ 의 총 비용 대신에 1 개 $\mathrm{CU}$ 의 비용에 4 배 이하의 가중치를 주 어 이전 $\mathrm{CU}$ 의 비용과 비교함으로써 현재 $\mathrm{CU}$ 가 4 개의 하위 $\mathrm{CU}$ 로 분리되는 것이 부호화 효율 측면에서 더 좋은지, 더 이상 분리되지 않고 종료하는 것이 복잡도 측면에서 더 좋 은 것인지 예측하는 것이다. 이와 같은 방법을 적용하면, 적응적으로 $\mathrm{CU}$ 부호화 깊이를 제한함으로써 더 많은 부호 화기의 복잡도를 감소시킬 수 있다.

\section{2. 고속 참조영상 선택 방법}

본 제안 방법에서는 상위 깊이 $\mathrm{CU}$ 와 현재 $\mathrm{CU}$ 사이의 움직임 정보의 상관성이 높음을 이용하여 상위 깊이 $\mathrm{CU}$ 의 움직임 정보를 이용하여 현재 움직임 예측을 수행하는 PU 의 참조영상 수를 제한한다. 그리고 제안하는 방법에서는 깊 이가 $(\mathrm{n}+1)$ 인 4 개의 $\mathrm{CU}$ 는 깊이가 $\mathrm{n}$ 인 $\mathrm{CU}$ 의 $\mathrm{PU}$ 를 확인하여 공간적으로 겹치는 위치에 있는 PU의 움직임 정보를 이용 한다. 예를 들어, 그림 5 에서 깊이가 $\mathrm{n}$ 인 $\mathrm{CU}$ 의 $\mathrm{PU}$ 가 $2 \mathrm{NxN}$ 일 때, 깊이가 $(\mathrm{n}+1)$ 인 4 개의 $\mathrm{CU}$ 중에 0,1 의 색인 값을 가 지는 $\mathrm{CU}$ 는 깊이가 $\mathrm{n}$ 인 $\mathrm{CU}$ 의 첫 번째 $\mathrm{PU}(\mathrm{top} 2 \mathrm{NxN})$ 의 움 직임 정보를 이용하고 2,3 의 색인 값을 가지는 $\mathrm{CU}$ 는 두 번째 PU(bottom $2 \mathrm{NxN}$ )의 움직임 정보를 이용한다.

그리고 깊이가 0 인 $\mathrm{CU}$ 의 움직임 정보를 그 아래 모든 
깊이의 $\mathrm{CU}$ 에서 사용하면 정확성이 낮아져서 성능이 떨어 지게 된다. 따라서 본 논문에서는 깊이 $\mathrm{d}$ 가 1,3 인 $\mathrm{CU}$ 에 대해서만 제안하는 방법을 적용한다. 즉, 깊이가 0,2 인 $\mathrm{CU}$ 들에 대해서는 가능한 모든 참조영상 후보에 대해서 움직 임 예측을 수행하고 깊이가 1 인 4 개의 $\mathrm{CU}$ 는 깊이가 0 인 $\mathrm{CU}$ 의 움직임 정보를 이용하며, 깊이가 3 인 4 개의 $\mathrm{CU}$ 는 깊 이가 2인 $\mathrm{CU}$ 의 움직임 정보를 이용한다. 위의 두 가지 방법 은 복잡도를 줄이면서 확률적으로 좀 더 신뢰성 있는 움직 임 정보를 이용함으로써, 더욱 정확한 참조영상의 결정을 하기 위함이다.

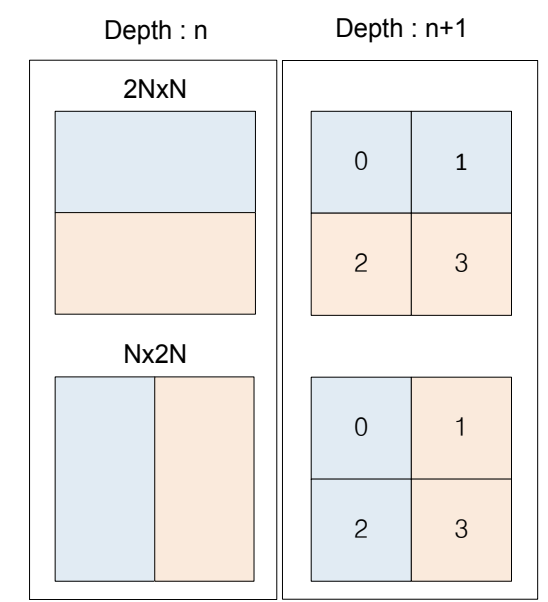

그림 5. 상위 $\mathrm{CU}$ 의 PU와 4개의 하위 $\mathrm{CU}$ 의 매핑

Fig. 5. Mapping between PUs of upper CU and four PUs of lower CU

참조영상의 후보의 수를 제한하는 알고리즘은 그림 6 과 같다. 먼저 상위 깊이 CU의 PU모드 정보를 확인하여 화면 간(Inter) 예측 모드 이고 Merge 모드가 아닌 경우, 즉 움직 임 예측을 수행한 경우, 상위 깊이 PU의 움직임 예측 방향 과 참조영상을 확인하고, 현재 부호화 하고자 하는 PU가 상위 깊이 PU에서 결정된 움직임 예측 방향에 대해 움직임 예측 수행 시, 그 예측 방향에 대한 참조영상 후보들 중 상 위 깊이 PU에서 사용한 참조영상에 대해서만 움직임 예측 을 행한다. 하지만 현재 PU가 상위 깊이 PU에서 선택된 예측 방향과 다른 방향에 대해 움직임 예측 수행 시, 그 방 향에서 허용되는 모든 참조영상에 대해서 움직임 예측을
수행한다.

그리고 상위 깊이 $\mathrm{CU}$ 의 $\mathrm{PU}$ 모드가 화면간 예측의 Merge 모드이거나 Skip 모드 인 경우, Merge의 후보로 사 용된 블록을 확인하고 그 블록의 움직임 정보를 이용하여 위의 알고리즘을 동일하게 수행한다. 만약 상위 깊이 PU가 양방향(Bi-directional) 예측인 경우, 현재 PU는 L0/L1 방향 에 대한 움직임 예측 시, 상위 깊이 PU의 각 방향 $(\mathrm{LO} / \mathrm{L} 1)$ 에 서 사용된 참조영상에 대해서만 움직임 예측을 수행한다. 그리고 상위 깊이 CU의 PU 모드가 화면내(Intra) 예측 모 드이거나 움직임 예측 방향이 $\mathrm{L} 0 / \mathrm{L} 0$ 혹은 $\mathrm{L} 1 / \mathrm{L} 1$ 예측인 경 우, 현재 PU는 각 움직임 예측 방향에 허용되는 모든 참조 영상에 대해 움직임 예측을 수행한다. 이와 같이 참조영상 을 제한함으로써 높은 복잡도를 필요로 하는 움직임 예측 의 복잡도를 상당히 감소시킬 수 있다.

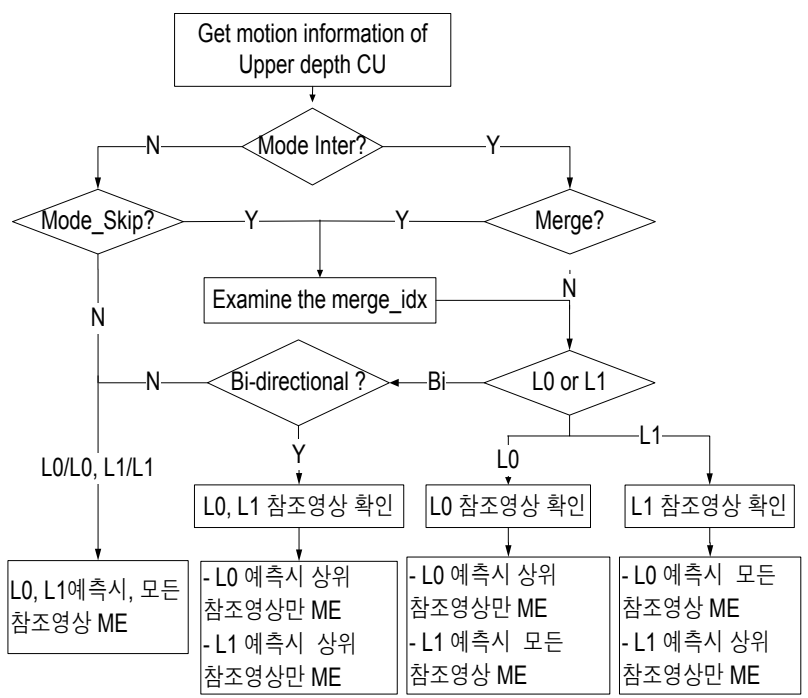

그림 6. 고속 참조영상 선택 알고리즘

Fig. 6. Fast algorithm of reference picture selection

\section{IV. 실험결과}

제안하는 알고리즘은 HEVC의 참조 소프트웨어 HM6.1 $\mathrm{rc}^{[8]}$ 에 구현하였으며, 표준화 과정의 실험을 위한 공통 실 험조건 ${ }^{[9]}$ 을 참조하여 각 영상별로 150 프레임씩 실험을 하 
였다. 그리고 실험환경은 임의접근(RA: Random Access)과 저지연B(LB: Low delay B)의 메인 프로파일에 대해서 실 험을 하였고, $\mathrm{QP}$ 는 22, 27, 32, 37로 설정하였다. 그리고 최대 부호화 깊이를 구하는 알고리즘에 사용되는 변수 $\mathrm{a}$ 는 실험을 통하여 2.8 로 설정하였다.

부호화 시간 변화량은 아래 식을 이용하여 백분율로 나 타내었다. $\mathrm{T}_{\mathrm{HM}}$ 은 $\mathrm{HM} 6.1 \mathrm{rcl}$ 으로 부호화 했을 때, 전체 부호 화 소요시간이고, $\mathrm{T}_{\mathrm{Prop}}$ 는 제안하는 알고리즘을 $\mathrm{HM} 6.1 \mathrm{rc1}$ 에 적용하였을 때 전체 부호화 시간을 나타낸다.

$$
\triangle T(\%)=\frac{T_{\operatorname{Pr} o p}}{T_{H M}} \times 100
$$

부호화 성능은 $\mathrm{y}, \mathrm{u}, \mathrm{v}$ 에 대한 $\mathrm{BD}-\mathrm{Rate}$ 을 사용하였다. 표 1 은 표준화에 사용되는 테스트 시퀀스이며, 그 중 $\mathrm{A} \sim \mathrm{E}$ 클 래스에 대해서 임의접근과 저지연B의 성능을 평가하는데 사용되는 클래스들을 각각 사용하였다. 표 2와 표 3 은 각각 RA-Main 와 LB-Main 부호화 구조를 사용하였을 때의 부 호화 및 복잡도 성능을 나타낸 것이다.

표 1. 테스트 시퀀스

Table 1. Test sequences

\begin{tabular}{|c|c|c|c|}
\hline Class & Resolution & Sequence name & Frame rate \\
\hline \multirow{4}{*}{ A } & \multirow{4}{*}{$2560 \times 1600$} & Traffic & $30 \mathrm{fps}$ \\
\hline & & PeopleOnStreet & $30 \mathrm{fps}$ \\
\hline & & Nebuta & $60 \mathrm{fps}$ \\
\hline & & StreamLocomotive & $60 \mathrm{fps}$ \\
\hline \multirow{5}{*}{ B } & \multirow{5}{*}{$1920 \times 1080$} & Kimono & $24 \mathrm{fps}$ \\
\hline & & ParkScene & $24 \mathrm{fps}$ \\
\hline & & Cactus & $50 \mathrm{fps}$ \\
\hline & & BQTerrace & 60fps \\
\hline & & BasketballDrive & 50fps \\
\hline \multirow{4}{*}{ C } & \multirow{4}{*}{$832 \times 480$} & RaceHorses & $30 \mathrm{fps}$ \\
\hline & & BQMall & $60 \mathrm{fps}$ \\
\hline & & PartyScene & $50 \mathrm{fps}$ \\
\hline & & BasketballDrill & $50 \mathrm{fps}$ \\
\hline \multirow{4}{*}{ D } & \multirow{4}{*}{$416 \times 240$} & RaceHorses & $30 \mathrm{fps}$ \\
\hline & & BQSquare & $60 \mathrm{fps}$ \\
\hline & & BlowingBubbles & $50 \mathrm{fps}$ \\
\hline & & BasketballPass & $50 \mathrm{fps}$ \\
\hline \multirow{3}{*}{ E } & \multirow{3}{*}{$720 p$} & FourPeople & $60 \mathrm{fps}$ \\
\hline & & Johnny & $60 \mathrm{fps}$ \\
\hline & & KristenAndSara & $60 \mathrm{fps}$ \\
\hline
\end{tabular}

표 2의 결과에서 제안한 알고리즘은 RA-Main 부호화 구 조에서 $\mathrm{HM}$ 대비 $1.2 \%$ 의 비트율 증가와 함께, 부호화 시간 이 $\mathrm{HM}$ 의 약 $61 \%$ 이므로 약 $39 \%$ 의 복잡도 감소를 보인다. $\mathrm{A}, \mathrm{B}$ 클래스 즉, 고해상도를 가지는 테스트 시퀀스에서 더 많은 복잡도 감소를 확인하였다. 표 3의 LB-Main 부호화 구조 경우에는 $1.0 \%$ 의 비트율 증가로 약 $30 \%$ 의 복잡도 감 소를 보인다. 특히, $\mathrm{E}$ 클래스의 경우에는 적은 비트율 증가 로 상당한 복잡도를 감소시킴을 확인하였고 이를 통해 평 탄한 영역이 많이 포함되어 있는 시퀀스에서 최대 부호화 깊이를 제한하는 알고리즘이 효율적임을 확인할 수 있다.

표 2. RA-Main 구조에서 제안 방법의 BD-rate과 시간 감소율 Table 2. BD-rate and time reduction ratio of the proposed method in RA-Main

\begin{tabular}{|c|ccccc|}
\hline & & \multicolumn{4}{|c|}{ Random Access Main } \\
\cline { 3 - 6 } & & $\mathrm{Y}$ & $\mathrm{U}$ & $\mathrm{V}$ & $\Delta \mathrm{T}$ \\
\hline Class & $\mathrm{A}$ & $1.3 \%$ & $1.4 \%$ & $1.5 \%$ & $60 \%$ \\
Class & $\mathrm{B}$ & $1.1 \%$ & $1.2 \%$ & $1.2 \%$ & $54 \%$ \\
Class & $\mathrm{C}$ & $1.2 \%$ & $1.3 \%$ & $1.0 \%$ & $64 \%$ \\
Class & $\mathrm{D}$ & $1.1 \%$ & $0.5 \%$ & $1.2 \%$ & $68 \%$ \\
Class & $\mathrm{E}$ & & & & \\
\hline \multicolumn{2}{|c|}{ Overall } & $1.2 \%$ & $1.1 \%$ & $1.2 \%$ & $61 \%$ \\
\hline
\end{tabular}

표 3. LB-Main 구조에서 제안 방법의 BD-rate과 시간 감소율 Table 3. BD-rate and time reduction ratio of the proposed method in LB-Main

\begin{tabular}{|cc|cccc|}
\hline & & \multicolumn{4}{|c|}{ Low delay B Main } \\
\cline { 3 - 6 } & & $\mathrm{Y}$ & $\mathrm{U}$ & $\mathrm{V}$ & $\Delta \mathrm{T}$ \\
\hline Class & $\mathrm{A}$ & & & & \\
Class & $\mathrm{B}$ & $1.1 \%$ & $0.7 \%$ & $0.7 \%$ & $70 \%$ \\
Class & $\mathrm{C}$ & $0.9 \%$ & $1.3 \%$ & $1.1 \%$ & $72 \%$ \\
Class & $\mathrm{D}$ & $1.2 \%$ & $0.8 \%$ & $1.4 \%$ & $75 \%$ \\
Class & $\mathrm{E}$ & $0.6 \%$ & $0.4 \%$ & $0.2 \%$ & $65 \%$ \\
\hline \multicolumn{2}{|c|}{ Overall } & $1.0 \%$ & $0.8 \%$ & $0.9 \%$ & $70 \%$ \\
\hline
\end{tabular}

또한 최대 부호화 깊이를 제한하는 알고리즘에 적용된 $a$ 의 값을 크게 할수록 부호화 효율은 떨어지지만 더 많은 복잡도를 감소시킬 수 있다. 그리고 표 2, 표 3을 통해, RA 구조에 비해 $\mathrm{LB}$ 구조에서 더 적은 복잡도 감소를 보이는 
이유는 참조영상을 제한하는 알고리즘과 연관이 있다. 즉, $\mathrm{RA}$ 구조의 경우, $\mathrm{L} 0$ 와 $\mathrm{L} 1$ 예측방향 모두에 대해서 참조영 상을 제한할 수 있지만, LB 구조의 경우, L0 예측방향만 존재하기 때문에 알고리즘이 미치는 영향이 RA 구조에 비 해 적기 때문이다. 실험결과를 통해, 제안한 알고리즘은 비 디오 부호화기의 부호화 시간을 상당히 감소시키며, 이는 다른 고속 알고리즘과 함께 사용될 수 있다.

\section{V. 결 론}

본 논문은 LCU의 부호화에 있어 공간적인 상관성을 이 용하여 부호화기의 복잡도를 감소시키기 위해 두 가지 방 법을 제안하였다. 첫 번째로 주변 LCU의 부호화 깊이 정보 와 율-왜곡 비용을 이용하여 현재 부호화하는 $\mathrm{LCU}$ 의 최대 부호화 깊이를 적응적으로 제한하는 알고리즘을 제안하였 다. 그리고 두 번째로 각 $\mathrm{CU}$ 의 최적의 $\mathrm{PU}$ 를 구할 때, 수행 하는 움직임 예측에서 상위 깊이 $\mathrm{CU}$ 의 움직임 정보를 이용 하여 현재 $\mathrm{PU}$ 의 참조영상을 제한하는 알고리즘을 제안하 였다. 본 논문에서는 상기 두 가지 방법을 결합하였으나 각 각 독립적으로 고속 부호화에 사용될 수 있다. 제안하는 방 법은 HM6.1rc1과 비교 실험한 결과 RA-Main 부호화 구조 에서 심각한 화질 열화 없이 약 $39 \%$ 의 부호화 시간을 감소 시킬 수 있었다.
제안한 방법은 공간적인 상관성에 기반하여 부호화 깊이 와 참조영상을 제안한 기법으로 추가적인 성능 개선을 진 행할 계획이며 다른 고속 알고리즘과도 결합되어 사용될 수 있을 것이다.

\section{참 고 문 헌}

[1] ITU-T Recommendation H.264 and ISO/IEC 14496-10, "Advanced video coding for generic audio visual services," May 2003.

[2] T. Wiegand, G. J. Sullivan, G. Bjontegarrd, and A. Luthra, "Overview of the H.264/AVC video coding standard," IEEE Trans. Circuits Syst. Video Technol., pp. 560-576, July 2003.

[3] "Call for Evidence on High-Performance Video Coding (HVC)," N10553, ITU-T Q6./16 Visual Coding and ISO/IEC JCT1/SC29/WG11 Coding of Moving Pictures and Audio, Apr. 2009.

[4] B. Bross, W.-J. Han, J.-R. Ohm, G. J. Sullivan, T. Wiegand, "High efficiency video coding (HEVC) text specification draft 6," JCTVC-H1003, 8th JCT-VC Meeting, San Jose, CA, USA, Feb. 2012.

[5] B. Bross, W. J. Han, J.-R. Ohm, G. J. Sullivan, T. Wiegand," WD1: Working Draft 1 of High-Efficiency Video Coding," JCTVC-C403, 3rd JCT-VC Meeting, Guangzhou, CN, Oct. 2010.

[6] "Early Termination of CU Encoding to Reduce HEVC Complexity," JCTVC-F045, 6th JCT-VC Meeting, Torino, IT, July 2011.

[7] "Coding tree pruning based CU early termination," JCTVC-F092, 6th JCT-VC Meeting, Torino, IT, July 2011.

[8] SVNserver: https://hevc.hhi.fraunhofer.de/svn/svn_HEVCSoftware/ tags/ HM-6.1 rc1/

[9] F. Bossen, "Common test conditions and software reference configurations," JCTVC-H1100, 8th JCT-VC Meeting, San Jose, CA, USA, Feb.2012.

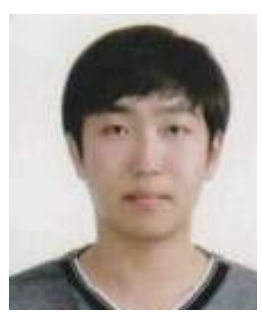

\section{이 상 용}

- 2010년 8월 : 한국항공대학교 항공전자공학과 학사 졸업

- 2012년 8월 : 한국항공대학교 항공전자공학과 석사 졸업

- 2012년 7월 현재 : 삼성전자 반도체총괄 System LSI 사업부

- 주관심분야 : HEVC, 고속 부호화 
저 자 소 개

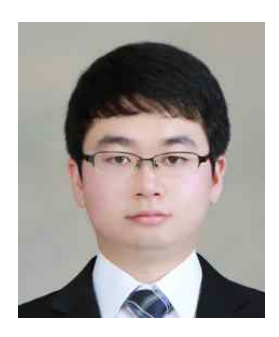

\section{김 동 현}

- 2012년 8월 : 한국항공대학교 항공전자공학과 학사 졸업

- 2012년 9월 현재 : 한국항공대학교 항공전자공학과 석사과정

- 주관심분야 : HEVC, 고속 부호화, 3D Video Coding

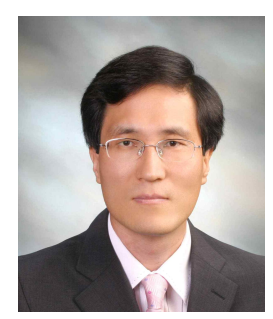

\section{김 재 곤}

- 1990년 2월 : 경북대학교 전자공학과 학사

- 1992년 2월 : KAIST전기 및 전자공학과 석사

- 2005년 2월 : KAIST전기 및 전자공학과 박사

- 1992년 3월 2007년 2월 : 한국전자통신연구원(ETRI) 선임연구원/팀장

- 2001년 9월 2002년 11월 : 뉴욕 콜롬비아대학교 연구원

- 2007년 9월 현재 : 한국항공대학교 항공전자 및 정보통신공학부 부교수

- 주관심분야 : 비디오 신호처리부호화, 디지털방송 미디어, 미디어 컨버전스, 멀티미디어 통신

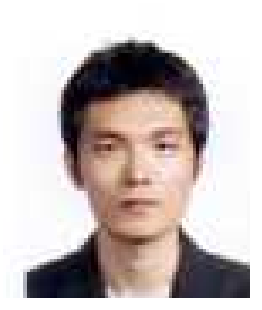

\section{최 해 철}

- 1997년 2월 : 경북대학교 전자공학과 학사

- 1999년 2월 : 한국과학기술원 전기및전자공학과(공학석사)

- 2004년 8월 : 한국과학기술원 전기및전자공학과(공학박사)

- 2004년 9월 2010년 2월 : 한국전자통신연구원(ETRI) 방송미디어연구부 선임연구원

- 2010년 3월 현재 : 한밭대학교 정보통신공학과 조교수

- 주관심분야 : 영상통신, 비디오 부호화, 패턴 인식

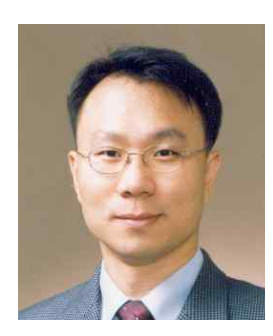

\section{김 진 수}

- 1991년 2월 : 경북대학교 전자공학과 학사

- 1993년 2월 : KAIST전기 및 전자공학과 석사

- 1998년 8월 : KAIST전기 및 전자공학과 박사

- 1995년 6월 2000년 3월 : 삼성전자 선임연구원

- 2008년 7월 2009년 6월 : 텍사스 주립대학교 교환교수

- 2000년 4월 현재 : 한밭대학교 정보통신공학과 교수

- 주관심분야 : 영상부호화, 디지털방송, 분산비디오부호화

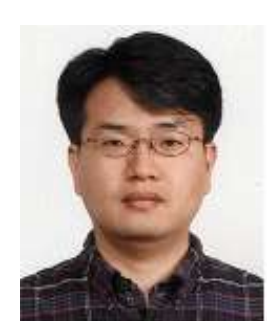

\section{최 진 수}

- 1990년 2월 : 경북대학교 전자공학과 공학사

- 1992년 2월 : 경북대학교 전자공학과 공학석사

- 1996년 2월 : 경북대학교 전자공학과 공학박사

- 1996년 5월 현재 : 한국전자통신연구원 책임연구원 재직

- 2001년 2월 2005년 3월 :한국전자통신연구원 데이터방송연구팀장

- 2008년 3월 현재 : 한국전자통신연구원 실감미디어연구팀장

- 2004년 10월 2006년 3월 : TTA 데이터방송프로젝트 그룹 의장

- 주관심분야 : 영상통신, UHDTV, 데이터방송 